\title{
HUBUNGAN DUKUNGAN KELUARGA DENGAN KEKAMBUHAN PADA PASIEN SKIZOFRENIA DI RUMAH SAKIT JIWA PROVINSI SUMATERA UTARA TAHUN 2018
}

\author{
Johani Dewita Nasution, Deliana Pandiangan \\ *Jurusan Keperawatan Poltekkes Kemenkes Medan
}

\begin{abstract}
Abstrak
Keluarga merupakan unit paling dekat dengan klien dan merupakan "perawat utama”bagi klien. Keluarga berperan dalam menentukan cara atau asuhan keperawatan yang diperlukan klien di rumah. Keberhasilan perawat di rumah sakit sia sia jika tidak diteruskan di rumah yang kemudian mengakibatkan klien harus dirawat kembali (kambuh). Peran serta keluarga sejak awal asuhan di rumah sakit akan meningkatkan kemampuan keluarga merawat klien di rumah sehingga keungkinan kambuh dapat dicegah. Pada penelitian ini metode yang digunakan Analitik dengan pendekatan cross sectional. Populasi dalam penelitian ini adalah keluarga pasien skizofrenia berjumlah 2026. Sedangkan sampel dalam peneltian 43 orang menggunakan accidental sampling. Metode pengumpulan data dengan penyebaran kuesioner berupa daftar pernyataan dengan lembar chek list. Dari hasil uji statistik diperoleh $p$ value $=0,2017$ ( $>>0,05$ )yang berarti tidak ada hubungan yang signifikan antara dukungan informasional dengan kekambuhan pasien skizofrenia, $p$ value dukungan penilaian=0,769 $(\mathrm{p}>0,05)$ yang berarti tidak ada hubungan yang signifikan antara dukungan penilaian dengan kekambuhan pasien skizofrenia, $p$ value dukungan instrumental $\mathrm{p}=0,017(\mathrm{p}<0,05)$ yang berarti ada hubungan yang signifikan antara dukungan instrumental dengan kekambuhan, dan $p$ value dukungan emosional $p=0,207$ yang berarti tidak ada hubungan yang signifikan antara dukungan emosional dengan kekambuhan pasien skizofrenia. Kesimpulan dari penelitian ini adalah tidak ada hubungan dukungan keluarga dengan kekambuhan pasien skizofrenia dan ada hubungan yang signifikan antara hubungan dukungan keluarga dengan kekambuhan pasien skizofrenia di rumah sakit jiwa Prof.dr.Muhammad Ildrem Provinsi Sumatera Utara tahun 2018.
\end{abstract}

Kata kunci : Dukungan keluarga, kekambuhan pasien skizofrenia

\section{PENDAHULUAN}

Kesehatan jiwa merupakan bagian yang integral dari kesehatan.Kesehatan jiwa bukan hanya sekedar terbebas dari gangguan jiwa,akan tetapi merupakan suatu hal yang dibutuhkan oleh semua orang. Kesehatan jiwa adalah perasaan sehat dan bahagia serta mampu mengatasi tantangan hidup,dapat menerima orang lain sebagai mana adanya serta mempunyai sikap positif terhadap diri sendiri dan orang lain (Depkes2005).

Menurut data dari WHO (2001), masalah gangguan kesehatan jiwa di seluruh dunia memang sudah menjadi masalah yang sangat serius. WHO (2001) menyatakan paling tidak ada satu dari empat orang di dunia mengalami masalah mental ,WHO memperkirakan ada sekitar 450 juta orang di dunia mengalami gangguan kesehatan jiwa (Rafei,2007).

Menurut $\mathrm{WHO}^{2}$ skizofrenia merupakan gangguan mental yang berat jalan dengan 1.183 diantaranya adalah kasus skizofrenia sedangkan untuk pasien jiwa yang di rawat di rawat inap pada Desember 2011 tercatat berjumlah 268 pasien, 209 diantanya adalah pasien skizofrenia.
Berdasarkan data Dinas Kesehatan Jawa Tengah (2013) terdapat 3/1000 dari 32.952.040 penduduk di Jawa Tengah terdiagnosa skizofrenia, jadi terdapat sekitar 98.856 orang mengalami gangguan jiwa skizofrenia (Sri,2008). Berdasarkan laporan tahunan Dinas Kesehatan Kabupaten Klaten angka kejadian gangguan jiwa pada tahun 2014 sebanyak 1.565 penderita.

Data dari rekam medis Puskesmas Cawas I Klaten didapatkan bahwa prevalensi penderita skizofrnia pada tahun 2012 ditemukan frekuensi kekambuhan sebanyak 530 kunjungan dari sejumlah 60 penderita, sedangkan laporan tahun 2013 mencatat angka kejadian kekambuhan penyakit skizofrenia sebanyak 449 kunjungan dari 55 penderita skizofrenia. Jumlah keseluruhan penderita skizofrenia di Puskesmas Cawas I Klaten pada tahun 2014 sebanyak 93 penderita tetapi yang mengalami kekambuhan sebanyak 55 pasien.

Berdasarkan survey kesehatan mental rumah tangga tahun 1999 yang dilakukan pada penduduk di 11 Kotamadya oleh jaringan epidemiologi psikiatri Indonesia ditemukan 185 dari 1000 penduduk menunjukkan adanya gejala gangguan kesehatan jiwa dan membutuhkan pelayanan kesehatan jiwa (Rafei, 2007). 
Berdasarkan kasus pada Februari 2014 di poliklinik Rumah Sakit Grhasia Sleman Yokyakarta, rata rata pasien gangguan jiwa yang berkunjung sebanyak 45 orang per hari, 10 terdiagnosa episode depresi, 3 terdiagnosa gangguan perkembangan pervasive, 4 diantaranya terdiagnosa epilepsi, 3 diantanya retardasi mental, 25 diantanya terdiagnosa skizofrenia, 17 diantarnya dinyatakan mengalami kekambuhan. Rata-rata tingkat kekambuhan yang dialami pasien skizofrenia sebanyak 3-8 kali per tahun.

Pencegahan kambuh atau mempertahankan klien di lingkungan keluarga dapat terlaksana dengan persiapan pulang yang adekuat serta mobilisasi fasilitas pelayanan kesehatan yang ada di masyarakat khususnya peran serta keluarga. Penelitian yang sama di inggris (vaugh dalam keliat 1992) memperlihatkan bahwa keluarga dengan ekspresi emosi yang tinggi (bermusuhan, mengkritik) diperkirakan kambuh dalam waktu 9 bulan. Hasilnya 57\% kembali dirawat dari keluarga dengan ekspresi emosi yang rendah. Terapi keluarga dapat diberikan untuk meniurunkan ekspresi emosi.

Jumlah penderita gangguan jiwa di Indonesia saat ini,berdasarkan data Kemenkes tahun 2013, mencapai lebih dari 28 juta orang. Dengan kategori gangguan jiwa ringan $11,6 \%$ dari populasi dan $0,46 \%$ menderita gangguan jiwa yang sampai sekarang belum diketahui penyebabnya. Meskipun pengetahuan kita tentang penyebab dan pathogenesis skizofrenia sangat kurang, masih diperkirakan angka kejadian skizofrenia di Indonesia 0,2\%-0,8\%setahun (Maramis,2004).

Pengobatan yang dapat dilakukan pada umumnya memiliki dua tahapan psikologis dalam proses penyembuhan pasien ynag mengalami gangguana jiwa yaitu tindakan berupa relaksasi dan meditasi salah satu metode pengobatan yang dapat dilakukan pada gangguan jiwa adaalah melalui metode medikasi yang secara medis diyakini menjadi salah satu untuk menangani masalah kesehatan jiwa dengan meditasi dimungkinkan seseorang dapat memperoleh ketenangan kestabilan emosi sehingga keadaannya akan lebih baik (Medical Record RSJ Medan 2013).

Menurut Rumah Sakit Jiwa Daerah Prof.Ildrem Provinsi Sumatera Utara jumlah pasien gangguan mental tahun 2017 berjumlah 2026 orang,dimana 80\% pasien tidak sembuh diakibatkan dukungan keluarga terhadap pasien kurang penuh.

\section{METODE PENELITIAN}

Desain yang digunakan dalam penelitian ini adalah analitik,dengan menggunakan metode pendekatan cross sectional,yaitu mengambil data 1 kali dan bermaksud untuk memperoleh suatu cross sectional pada populasi dan waktu yang disediakan dengan pengumpulan data saat ini, yang bertujuan untuk menemukan hubungan dukungan keluarga terhadap kekambuhan pasien skizofrnia di Rumah Sakit Jiwa Prof.Ildrem Sumatera Utara Tahun 2018.

Populasi dalam penelitian ini adalah keluarga pasien skizofrenia yang menemani anggota keluarga skizofrenia berkunjung ke rumah sakit jiwa sebanyak 2026.

Sampel dalam penelitian ini adalah 43 responden dengan Tehnik pengambilan sampel dilakukan dengan cara sampling accidentally yaitu tehnik penentuan sampel berdasarkan kebetulan, yaitu siapa saja yang secara kebetulan bertemu dengan peneliti dapat digunakan sebagai sampel. Bila dipandang orang yang kebetulan ditemui cocok sebagai sumber (Nursalam, 2003)

$$
\mathrm{n}=\frac{\mathrm{N}}{1+\mathrm{n}(\mathrm{d})}
$$

Keterangan :

$$
\begin{aligned}
& \mathrm{N} \quad \text { : Besar Populasi } \\
& \mathrm{n} \quad \text { : Besar Sampel } \\
& \mathrm{D} \quad \text { : Nilai Kepercayaan }(0,15)^{2} \\
& \mathrm{n}=\frac{2026}{1+2026(0,15)^{2}} \\
& =\frac{2026}{1+2026(0,0225)} \\
& =\frac{2026}{1+45,585} \\
& =\frac{2026}{46,585} \\
& \mathrm{~N}=43,49 \\
& \mathrm{~N}=43 \text { responden }
\end{aligned}
$$

\begin{tabular}{|c|c|c|c|}
\hline Tabel 4.2 & \multicolumn{3}{|c|}{$\begin{array}{l}\text { Distribusi Frekuensi Dukungan Penilaian } \\
\text { Keluarga Dengan Kekambuhan Pada Pasien } \\
\text { Skizofrenia }\end{array}$} \\
\hline Duk & kungan penilaian & Jumlah & $\begin{array}{l}\text { Percent } \\
\text { (\%) }\end{array}$ \\
\hline & 1. Baik & 21 & $48,8 \%$ \\
\hline & 2. Tidak baik & 22 & $51,2 \%$ \\
\hline \multicolumn{2}{|c|}{ Jumlah } & 43 & $100 \%$ \\
\hline
\end{tabular}

\section{HASIL PENELITIAN}



Berdasarkan tabel 4.1.diketahui bahwa mayoritas keluarga yang memliki dukungan informasional yang baik sebanyak 22 orang responden (51,2\%). Sedangkan minoritas keluarga yang memiliki dukungan informasional yang kurang baik sebanyak 21 orang responden (48,8\%).

Berdasarkan tabel 4.2. diketahui bahwa mayoritas keluarga yang memiliki dukungan penilaian yang kurang baik sebanyak 22 orang responden (51,2\%), sedangkan minoritas keluarga yang memliki dukungan penilaian kurang sebanyak 21 orang responden (49\%). 
Tabel 4.3 Distribusi Frekuensi Dukungan Instrumental Keluarga Dengan Kekambuhan Pada Pasien Skizofrenia

\begin{tabular}{|c|c|c|}
\hline $\begin{array}{c}\text { Dukungan } \\
\text { instrumental }\end{array}$ & Jumlah & Percent (\%) \\
\hline 1. $\quad$ Baik & 20 & $46,5 \%$ \\
\hline 2. Tidak baik & 23 & $53,5 \%$ \\
\hline Jumlah & 43 & $100 \%$ \\
\hline
\end{tabular}

Berdasarkan tabel 4.3. diketahui bahwa mayoritas keluarga yang memiliki dukungan instrumental yang kurang baik sebanyak $23 \%$ orang responden (53,5\%),sedangkan minoritas keluarga yang memiliki dukungan instrumental yang baik sebanyak 20 orang responden (46,5\%).

Tabel 4.4. Distribusi Frekuensi Dukungan Emosional Keluarga Dengan Kekambuhan Pada Pasien Skizofrenia

\begin{tabular}{lcc}
\hline $\begin{array}{l}\text { Dukungan } \\
\text { emosional }\end{array}$ & Jumlah & Percent (\%) \\
\hline 1. Baik & 10 & $23,3 \%$ \\
2. Tidak baik & 33 & $76,7 \%$ \\
\hline Jumlah & 43 & $100 \%$ \\
\hline
\end{tabular}

Berdasarkan tabel 4.4. diketahui bahwa mayoritas keluarga yang memiliki dukungan emosional kurang baik sebanyak 33 orang orang responden (76,7\%), sedangkan minoritas keluarga yang memiliki dukungan emosional baik sebanyak 10 orang responden (23,3\%).

Tabel 4.5. Distribusi Frekuensi Responden Kekambuhan Pada Pasien Skizofrenia

\begin{tabular}{lll}
\hline Kekambuhan & Jumlah & Percent (\%) \\
\hline Kambuh & 20 & 46,5 \\
$\begin{array}{l}\text { Tidak } \\
\text { kambuh }\end{array}$ & 23 & 53,5 \\
Jumlah & 43 & 100 \\
\hline
\end{tabular}

Berdasarkan tabel 4.5. diketahui bahwa responden kambuh sebanyak 23 orang (53,5\%) dan yang tidak kambuh sebanyak 20 orang (46,5\%).

\section{PEMBAHASAN}

Dukungan informasional yang diteliti dalam peneltian adalah meliputi jaringan komunikasi dan tanggung jawab bersama. Pada dukungan ini keluarga sebagai penghimpun informasi dan penberi informasi termasuk di dalamnya mmberikan nasihat dn menjelaskan pengobatan kepada pasien skizofrenia.

Berdasarkan hasil chi sguare (person chi sguare) dukungan keluarga informasional dengan kekambuhan pasien skizofrenia diperoleh nilai $p$ value $=0,280(p>0,05)$ hal ini menunjukkan secara statistik bahwa tidak terdapat hubungan yang signifikan antara dukungan emosional dengan kekambuhan pasien skizofrenia.

Dari hasil tersebut diketahui bahwa keluarga yang memiliki dukungan informasional yang baik dan tidak baik menyebabkan kekambuhan pada pasien skizofrenia tetapi apabila dukungan informasional nya ditingkatkan maka tidak akan meningkatkan kekambuhan pada pasien skizofrenia.

Hasil penelitin ini sejalan dengan penelitian yang dilakukan Gunawan (2010) bahwa tidak terdapat hubungan yang bermakna antara dukungan informasional dengan kekambuhan pada pasin skizofrenia yang berarti semakin banyak dukungan keluarga yang diberikan maka semakin mengurangi kekambuhan pada pasien siofrenia.

Dari hasil penelitian dalam dukungan informasional yang baik masih terdapat pasien yang kambuh sebanyak 8 orang disebabkan keluarga sudah memahami cara pemberian dukungan informasional tetapi keluarga masih sepele, dan tidak berniat sepenuhnya untuk memberikan dukungan inormasional.

Maka dapat diasumsikan bahwa dukungan informasional. Seharusnya diberikan sejak awal pasien mengalami gangguan jiwa hingga dirawat dirumah sakit dan setelah pulang ke rumah. Keluarga juga harus mengerti dalam memberikan dukungan informasional itu penting untuk pasien agar kebutuhnnya terpenuhi. Jika kebutuhan pasien telah terpenuhi maka kekambuhan akan berkurang.

Berdasarkan hasil chi sguare (person chi sguare) dukungan emosional keluarga dengan kekambuhan pasien skizofrenia diperoleh nilai $p$ value $=0,280(\mathrm{p}>0,05)$ hal ini menunjukkan secara statistik bahwa tidak terdapat hubungan yang signifikan antara dukungan penilaian dengan kekambuhan pasien skizfrenia.

Hasil penelitian ini sejalan dengan penelitian yang dilakukan oleh Gunawan (2010) bahwa tidak terdapat hubungan yang bermakna antara dukungan penilaian dengan kekambuhan pada pasien skizofrenia ,yang berarti bahwa semakin baik dukungan penilaian yang diberikan maka semakin memperkecil angka kekambuhan pasien skizofrenia

Dari hasil penelitian dukungan penilaian yang baik masih terdapat responden yang kambuh sebanyak 10 orang disebabkan karena respon keluarga kurang peduli terhadap kemampuan pasien dalam menjalani pengobata seperti pujian dan motivasi.

Maka dapat diasumsikan bahwa keluarga seharusnya peduli dan memberikan respon yang baik terhadap hal hal yang dilakukan responden.keluarga juga harus mengerti dalam memberikan dukungan penilaian itu penting untuk pasien agar kebutuhannya terpenuhi. Jika kebutuhan pasien terpenuhi maka kekambuhan akan berkurang.

Berdasarkan hasil chi sguare (person chi sguare) dukungan keluarga emosional dengan kekambuhan pasien skizofrenia diperoleh nilai $p$ value $=0,006(p>0,05)$ hal ini menunjukkan secara statistik bahwa terdapat hubungan yang signifikan antara dukungan emosional dengan kekambuhan pasien skizofrenia.

Hasil penelitian ini sejalan dengan penelitian yang dilakukan oleh Erika ( 2010) bahwa terdapat hubungan yang bermakna antara dukungan instrumental dengan kekambuhan pasien skizofrenia, yang berarti bahwa semakin baik dukungan instrumental yang diberikan maka semakin mengurangi kekambuhan pasien skizofrenia.

Dari hasil penelitian dukungan instrumental yang baik masih terdapat responden yang kambuh sebanyak 14 
orang disebabkan sebagian keluarga masih belum memberikan sepenuhnya kebutuhan pasien seperti makanan, pakaian dan lain sebagainya.

Maka dapat diasumsikan bahwa dukungan instrumental seharusnya dukungan instrumental itu diberikan sejak awal pasien masuk rumah sakit hingga setelah pulang ke rumah. Keluarga juga harus mengerti dalam memberikan dukungan instrumental itu penting untuk pasien agar kebutuhannya terpenuhi. Jika kebutuhan pasien terpenuhi maka tingkat kekambuhan akan berkurang.

Berdasarkan hasil chi sguare (person chi sguare) dukungan keluarga emosional dengan kekambuhan pasien skizofrenia diperoleh nilai $p$ value $=0,04(p<0,05)$ hal ini menunjukkan secara statistik bahwa terdapat hubungan yang signifikan antara dukungan emosional dengan kekambuhan pasien skizofrenia.

Dari hasil penelitian dukungan emosional dengan kekambuhan pada pasien skizofrenia di atas diketahui bahwa keluarga yang memiliki dukungan emosional yang baik dan tidak baik menyebabkan kekambuhan pada pasien skizofrenia tetapi apabila dukungan emosional ditingkatkan maka tidak akan mengakibatkan kekambuhan pada penderita skizofrenia.

Pendapat ini didukung oleh oleh cabb and nindra (2002) dengan dukungan emosional melibatkan keinginan untuk percaya kepada orang lain sehingga penderita yang bersanggkutan menjadi yakin bahwa orang lain mampu memberikan perhatian cinta dan kasih sayang,dan rasa empati kepadanya shingga mampu mengtasi perasaan negative yang husus disebabkan oleh stress.

Maka dapat diasumsikan bahwa dukungan emosional seharusnya diberikan sejak awal pasien masuk rumah sakit jiwa dan setelah pulang ke rumah agar kebutuhan pasien terpenuhi. Jika kebutuhan pasien terpenuhi maka pasien tidak akan mengalami kekambuhan lagi.

\section{KESIMPULAN}

Terdapat hubungan dukungan keluarga terhadap kekambuhan pasien skizofrenia di Rumah Sakit Jiwa Prof.dr.Muhammad ildrem Provinsi Sumatera Utara.

\section{DAFTAR PUSTAKA}

Arikunto. (2006). Prosedur Penelitian Suatu Pendekatan Praktik. Jakarta : Kineka Cipta

Friedman, M. (1998). Keperawatan keluarga. ed-3. Jakarta : EGC

Gusti, S. (2016). Buku Ajar Asuhan Keperawatan keluarga. Jakarta : trans info media

Herman, A. (2015). Buku Ajar Asuhan Keperawatan Jiwa, Yogyakarta : Nuha Medika

Kelliat, A, dkk. (2012). Keperawatan Kesehatan Jiwa. Jakarta : EGC

Kelliat, A. (2011). Manajement Kasus

Gangguan Jiwa CMHN. Jakarta : EGC.

Madriffa, dkk. (2015). Hubungan Peran Kelurga Dengan Kekambuhan Pasien Skizofrenia di wilayah kerja puskesmas cawan klaten,jurnal penelitian Surakarta:universitas muhammadiyah.

Maramis, F. (2009). Catatan Ilmu Kedokteran Jiwa Edisi Dua. Surabaya : Airlangga Universit Press.

Nasir, A, dkk. (2011). Dasar Dasar Keperawatan Jiwa. Jakarta : Salemba Medika

Notoatmodjo, S. (2012). Metode Penelitian Kesehatan. Jakarta : Rineka Cipta

Politeknik Kesehatan Medan, (2015). Panduan Penyusunan Karya Tulis Ilmiah . Medan

Prabowo ,Eko. (2014). Buku Ajar Keperawatan Jiwa Yogyakarta : Nuha Medika

Rekam Medis . (2017). RSJ.Prof. Dr.Muhammad Ildrem.

Saputra, N. (2010). Hubungan Dukungan Keluarga dengan Kekambuhan pasien skizofrenia di poliklinik rumah sakit jiwa daerah provinsi sumatera utaramedn.Skripsi. Medan: Universitas Sumatera Utara

WHO. (2012). Skizofrenia. Dibuka pada 12 Januari 2018 pada website http://www.who.int/mental health/management/skizofrenia/en/

Yudi, P, dkk. (2015). Hubungan Keluarga Pasien Terhadap Kekambuhan Skizofrenia Di Badan Layanan Umum Daerah (BLUD) Rumah Sakit Jiwa Aceh.Jurnal Penelitian . Banda Aceh : Universitas Syiah Kuala 